\title{
ARne Naess E os Oito Pontos DA ECOLOGIA PROFUNDA
}

João Luiz Hoefel

Resumo: Neste artigo procuramos apresentar as idéias básicas da Ecologia Profunda, em especial a abordagem desenvolvida por Arne Naess, bem como elaborar algumas considerações sobre as diferenças que tem sido apontadas por Naess e outros autores entre a Ecologia Profunda e a Superficial.

UNITERmos: Ecologia Profunda - Ecofilosofia - Sustentabilidade - Valor intrínseco Antropocentrismo - Problemas Ambientais - Movimento Social.

\section{INTRODUÇÃO}

Este trabalho tem por finalidade apresentar alguns elementos básicos do movimento filosófico conhecido como Ecologia Profunda, elaborado na década de 70, com o objetivo de compreender, articular e propor soluções para a problemática ambiental. Longe de esgotar todas as possibilidades de interpretação, desdobramentos e críticas que a Ecologia Profunda sofreu e tem sofrido, a atenção deste texto concentrou-se na apresentação de seus antecedentes históricos, suas características principais, em especial seus oito pontos básicos, e os aspectos de distinção entre ecologia profunda e superficial. Em função das diferentes interpretações que o termo Ecologia Profunda sofreu nos últimos anos, buscou-se 
expressar aqui idéias e opiniōes que refletissem o pensamento de Arne Naess (1989) - o criador deste termo, bem como daqueles que têm trabalhado como seus colaboradores próximos.

\section{ARne NaEss e a Ecologia Profunda}

O termo "Ecologia Profunda" foi criado pelo filósofo norueguês Arne Naess em um artigo intitulado "The shallow and deep, long-range movement. A summary", publicado em 1973 no periódico Inquiry (Naess, 1989).

O trabalho de Arne Naess no campo da ecofilosofia segue uma longa trajetória na qual ele fez contribuições significativas em áreas específicas da filosofia, tais como semântica, filosofia da ciência e a exposição sistemática das filosofias de Spinoza e Gandhi.

Arne Naess (1989) faz a distinção entre dois grandes movimentos que ele denomina "Ecologia Superficial" e "Ecologia Profunda", esclarecendo que os termos Superficial e Profunda não dizem respeito a uma escala de valores, mas a um questionamento que nos leva a aprofundar nossa visão sobre as causas da crise ambiental que vivemos hoje.

Wittgenstein apontou para o fato de que o pensamento comum é como nadar na superfície - muito mais fácil do que nadar nas profundezas e para Naess (1989) esta metáfora pode ser aplicada quando se aborda conflitos ecológicos.

Segundo Naess (1990), o termo Ecologia Profunda tem sua origem com a publicação do livro Primavera Silenciosa, de Rachel Carson (1963). Naess aponta para o fato de que Rachel Carson provocou controvérsias sobre a cooperação entre o departamento de agricultura dos Estados Unidos e a indústria química, ao questionar de uma forma profunda as premissas da sociedade industrial, revelando forças políticas, econômicas e tecnológicas que poderiam levar a uma primavera silenciosa. 
O trabalho de Rachel Carson (1963), entre outras contribuições, alertou sobre a ocorrência de desastres ecológicos criados pelo homem, motivou esforços para a criação e implementação de novas políticas e de açòes individuais que levassem em conta a problemática ambiental, bem como estimulou a busca de uma nova cosmovisão voltada para a questão do significado à vida, especialmente quando se tem por base uma ética ambientalmente desperta.

Para Naess (1990), foi o aspecto ecofilosófico do trabalho de Carson que motivou o uso do termo Ecologia Profunda, assim como o desenvolvimento de um tipo de filosofia ambiental e o surgimento de um movimento social com o mesmo nome. Salienta também que o termo ecologia profunda engloba sempre dois aspectos: um filosófico e outro como base para um ativismo social, demandando mudanças em todos os aspectos da vida humana.

Em seu trabalho sobre a história da ecologia profunda, Naess (1990) aponta para o fato de que as atitudes e opiniões características deste movimento são encontradas em muitas culturas e que desta forma ele apresenta tanto um aspecto novo enquanto sistematização filosófica quanto um aspecto tradicional, na medida em que reflete a sabedoria e o conhecimento presentes entre uma diversidade de sistemas culturais.

Devall \& Sessions (1985), em trabalho semelhante sobre os precursores do movimento em ecologia profunda nos Estados Unidos, colocam a importância dos trabalhos de John Muir, com sua visão de igualdade biocêntrica e sua ativa liderança em questões de políticas públicas afetando áreas silvestres. O movimento do Romantismo do tempo de Goethe até os dias atuais também é apontado como o fornecedor de visões importantes. A história da divisão entre os grupos comprometidos de uma forma profunda, social e politicamente, e os envolvidos no movimento da ecologia superficial está ligada com a história da interaçào entre o Iluminismo e o Romantismo, 
especialmente no que se refere ao aspecto antropocêntrico em relação ao ecocêntrico.

Um outro aspecto ressaltado por Naess (1989) refere-se à função positiva da crise ecológica, que a seu ver é de renovar o interesse geral sobre qual é o papel da humanidade. Por e para que estamos aqui? Para destruir o planeta? Por que devemos fazer isto? Existirào propósitos básicos que tornem necessário ameaçar a riqueza e diversidade de vida? Para ele o movimento chamado superficial não coloca tais questòes no centro de suas atenções por crer que os distúrbios ecológicos são poucos, razoavelmente bem conhecidos e capazes de serem eliminados como outros distúrbios já foram, através do conhecimento técnico e de um inteligente gerenciamento de recursos. $\mathrm{E}$, além disto, por não combinar a preocupação ambiental com uma avaliação crítica das tendências dominantes de crescimento econômico, como se isto fosse um bem inquestionável.

Por outro lado, para Naess

"é trabalho do filosofo ir mais profundo nos problemas e situagões que a principio podem parecer simples ou óbvias, expondo suas raizes, de forma a revelar estruturas e conexões que então se tornarão visiveis. É por isto que uma ecologia filosófica é uma ecologia profunda. O termo profundo aplica-se à profundidade com que se observa na busca das raizes dos problemas, negandose ignorar o trabalbo que pode revelar uma inesperada vastidão do problema. Não se deve nunca restringir os limites do problema só para fazer uma solução mais fácil aceitável"'. (1989, p.12)

Naess cm colaboração com George Sessions (1989) elaborou uma caracterização simples e clara da Ecologia Profunda, que denominou plataforma de princípios básicos do movimento da Ecologia Profunda. Ao publicar tais princípios ressaltou que estes não tinham um sentido absoluto, mas que eram passíveis de mudanças e transformações na medida em que o movimento e as idéias relacionadas com a Ecologia Profunda fossem amadurecendo. É dentro desta perspectiva que, em 1992, os pontos foram reapresentados, em sua última versão, na forma que segue abaixo:

Temáticas, Campinas, 4(7):69:89, jan./jun. 1996 
"1. O florescimento de seres vivos bumanos e não bumanos tem valor intrinseco. O valor de seres não bumanos é independente de sua utilidade para propósitos bumanos.

2. A riqueza e a diversidade de formas de vida na Terra, incluindo formas de culturas bumanas, têm valor intrinseco.

3. Os seres humanos não têm o direito de reduzir esta riqueza e diversidade, exceto para satisfazer necessidades vitais.

4. O florescimento da vida e culturas bumanas é compativel com uma população bumana substancialmente menor.

5. A presente interferência bumana com o mundo não bumano é excessiva e a situação está piorando.

6. Os pontos acima mencionados indicam que mudanças são necessárias na forma dominante com que os humanos ate agora têm se comportado em sua relação com a Terra como um todo. Estas mudanças irão, de uma maneira fundamental, afetar estruturas politicas, sociais, tecnológicas, econômicas e ideológicas.

7. A mudança ideológica em paises ricos será principalmente a de aumentar o apreço por qualidade de vida, do que a busca de um alto padrão material, desta forma preparando um estado global para um desenvolvimento ecologicamente sustentavel.

8. Aqueles que subscrevem os pontos mencionados têm uma obrigação direta ou indireta de tentar implementar as mudanças necessárias por meios não violentos"(Rothenberg, 1993, p.127).

Segundo Naess (1989), esta plataforma é para ser olhada não como um pronunciamento dogmático, mas como um ponto de partida para enfocar nosso pensamento em uma filosofia ambiental que estimule a elaboração de questões básicas sobre o lugar de nossa espécie na natureza, na esperança de que tais reflexões levem a soluções para a crise ambiental que vivemos hoje.

$\mathrm{Na}$ mesma obra, ele estabelece uma distinção entre a filosofia e o movimento da Ecologia Profunda. Um movimento pode ser inspirado por slogans e tocar milhões de pessoas enquanto uma filosofia é algo diferente, pois é um caminho de questionamento, um método que coloca os pensadores em suas próprias e diversas rotas. Talvez subindo a mesma montanha, mas escolhendo o caminho mais apropriado para cada indivíduo escalar. 
Historicamente, a expressào Ecologia Profunda tem se tornado uma frase atrativa para muitas pessoas que tendem a utilizá-la sem observar qual o seu significado original. Existem aqueles que a utilizam para se autodenominar verdadeiros e sérios ambientalistas, e há outros que a utilizam como um substituto para o termo radical, levando seus oponentes a criticálos por irem muito além no que diz respeito a problemas reais e soluções possíveis. Pelo fato de a expressão ter sido muitas vezes distorcida e utilizada em tantas direções distintas da proposta inicial, é necessário esclarecer alguns pontos. A Ecologia Profunda não deveria ser usada como um sinônimo de extremismo, mas como uma base para a determinação de que mudanças são importantes para a realização da meta de um mundo sustentável. Ela não deveria ser um jargão, mas um instrumento que gradualmente poderá levar a um caminho viável.

A Ecologia Profunda, segundo Naess (1989), é uma tentativa em processo e não uma solução acabada. Ela sugere que qualquer ser vivo ou aspecto do mundo vivo não deveria ser utilizado como um meio em direção a um fim, pois a vida tem valor intrínseco e isto deveria estar presente em todas as ações e atividades humanas. Isto nào implica que a natureza é algo para ser mantida intocada, mas que deveria ser modificada somente a partir do momento em que a consciência de seu valor fundamentasse qualquer intervenção.

A atitude de reexaminar os limites do mundo natural e do mundo humano tem considerável conseqüências para práticas e teorias éticas e políticas. A contribuição filosófica deve caminhar com o desenvolvimento científico e assim é proposto o termo Ecosofia - ecologia misturada com filosofia, ou seja sabedoria relacionada com ação. Apoiados na Ecosofia, políticos ou tomadores de decisão não pressionarão só por mais ciência mas farào isto na mesma intensidade em que pressionarão por sabedoria. Não importa quanto mais obtivermos da ciência, pois a ignorância aumentará se não soubermos as conseqüências do que faremos através da ciência.

Desta forma, Naess (1989) afirma: 
Os oito princípios, de acordo com Naess (1989.a), não deveriam impedir a existência de diferenças em visòes científicas, metafísicas e religiosas, mas estas deveriam ter sempre uma base ecológica ecocêntrica e não antropocêntrica. Esta abordagem tem levado alguns críticos a pensar que existe um ponto de vista extremado que tende a por a natureza antes das pessoas.

De acordo com Naess (1986), somente mudanças profundas e significativas na estrutura da sociedade humana serão eficientes para alterar o atual estado de deterioração ambiental, embora a argumentação da ecologia superficial diga que não é necessário ir tão profundo nesta direção. Existe um lado da Ecologia Profunda que implica numa renovação da forma pela qual vemos o mundo, desenvolvendo uma forma de percepção sistêmica que restabelece as interconexões presentes na rede da vida das quais nós somos sempre uma parte.

\section{CONSIDERAÇÕES SOBRE OS OITO PONTOS BÁSICOS DA ECOLOGIA PROFUNDA}

Nos últimos anos diversos autores (Devall \& Sessions, 1985; Devall, 1993; Fox, 1990; McLaughlin, 1993; Naess, 1989; Sessions, 1994) têm procurado esclarecer e desenvolver as idéias contidas nos oito pontos básicos expostos anteriormente. Nos tópicos a seguir procuraremos apresentar estas contribuições de forma a trazer subsídios para maior compreensão dos elementos básicos da Ecologia Profunda.

\section{Ponto 1}

O florescimento dos seres vivos bumanos e não bumanos tem valor intrinseco. $O$ valor dos seres não bumanos é independente de sua utilidade para propósitos bumanos.

Segundo Devall \& Sessions (1985), valor intrínseco, da forma como é empregado neste ponto, significa que o valor de um objeto natural não é dependente de um observador humano, nem de um valor monetário que lhe 
possa ser atribuído. Esta afirmativa refere-se a uma conceituação mais ampla de vida e de seres vivos, conforme expressa pela Ecologia Profunda, e não somente da forma como é definida pelos biólogos. Os termos vida $\mathrm{e}$ seres vivos referem-se também a elementos que são normalmente classificados como não vivos tais como rios, paisagens, montanhas, ecossistemas e a Terra como um todo.

Para McLaughlin (1993), esta afirmativa é essencialmente a negação de uma visão antropocêntrica e uma afirmação de que tanto a vida humana quanto a não humana devem ter condições favoráveis para o seu desenvolvimento. Aponta também para o fato de que a busca por alguma espécie de valor na natureza nào humana, seja ele inerente, intrínseco ou alguma outra forma de valor não antropocêntrico, parece necessária pelo fato de não termos elaborado totalmente uma ética ambiental adequada. E para Naess (1989) a própria noção de uma ética ambiental deveria desaparecer no momento que os seres humanos se percebessem como uma parte integrante da natureza. Da mesma forma como respirar é um ato automático em seres vivos, a incorporação de uma consciência sistêmica automaticamente deveria levar a uma atitude não antropocêntrica com relação a natureza.

\section{Ponto 2}

A riqueza e diversidade de formas de vida na Terra, incluindo formas de culturas bumanas, têm valor intrinseco.

Segundo Devall (1993), esta afirmação tem como objetivo ressaltar a importância da complexidade e da diversidade biológica, pois na teoria ecológica todas as espécies têm uma função a desempenhar e desta forma possuem valor em si mesmas. As espécies ditas inferiores não são consideradas apenas como suportes para formas superiores de vida, e o ecocentrismo rejeita a posição de que algumas formas de vida , tais como a humana, têm um valor inerente e superior à outras formas de vida. Devall (1993) aponta também para o fato de que complexidade não é sinônimo de complicação e que a civilização contemporânea exibe muita complicação mas 
não é mais complexa do que a realidade multifacetada manifestada por tribos primitivas.

Naess (1989) argumenta que as chamadas espécies vegetais e animais denominadas simples, inferiores ou primitivas contribuem de maneira fundamental para a riqueza e diversidade da vida, tendo valor em si mesmas e não sendo simples etapas em direção as chamadas formas superiores de vida. Esta afirmativa pressupooe que a vida enquanto um processo evolutivo implica em um aumento na riqueza e diversidade de espécies e, segundo o autor, de um ponto de vista ecológico, complexidade e simbiose são condições para máxima diversidade.

Para McLaughlin (1993) esta afirmativa é uma oposição à imagem de cvolução que culmina em formas superiores de vida. Envolve uma revisão $\mathrm{em}$ nossas idéias e conceitos sobre o desenvolvimento da vida e uma mudança na forma de compreender evolução como um "progresso de formas inferiores" para "formas superiores de vida", para uma compreensão que a vê como uma expressão de múltiplas e diversas formas de vida. Ao invés de observar a natureza como uma hierarquia de seres de baixo para cima, ou seja do inferior para o superior, a idéia de diversidade acolhe diferenças e rejeita qualquer padrão único de excelência.

A Ecologia Profunda enfatiza o valor da diversidade tanto a nível de atividades humanas quanto no resto da natureza. A diversidade é valorizada no que diz respeito à diferenças em termos de abordagens culturais bem como em relação a esforços para proteger a diversidade de culturas humanas.

\section{Ponto 3}

Os seres bumanos não têm direito de reduzir a riqueza e diversidade exceto para satisfazer necessidades vitais.

Segundo McLaughlin (1993), a questão central aqui colocada é a distinção entre necessidades vitais e necessidades criadas pela sociedade de consumo. Para o autor não é possivel estabelecer limites precisos com rela- 
ção a esta questão, em função de diferenças culturais que irão determinar formas distintas de se satisfazer necessidades vitais.

Naess (1989) coloca que este ponto talvez seja um pouco radical mas nos estimula a analisar de uma forma profunda nossos conceitos sobre necessidades e o quanto de realidade eles contêm, em especial em sociedades industriais ricas.

O termo necessidades vitais, para Naess (1989) e Devall \& Sessions (1985), é deixado deliberadamente vago para permitir uma amplitude de julgamentos. Devall (1993) apresenta como necessidades vitais as biológicas, sociais e espirituais e sugere que clas são satisfeitas dentro de contextos ambientais, técnicos e culturais com as mais distintas características. Para este autor existem diversas maneiras de se suprir cada necessidade vital mas deve-se ter em mente a possibilidade disto ser feito da forma menos destrutiva do ponto de vista ambiental.

\section{Ponto 4}

O florescimento da vida e culturas bumanas é compativel com um decréscimo substancial na população bumana. O florescimento da vida não bumana requer tal decréscimo.

Segundo McLaughlin (1993), uma vez que se perceba ou se valorize outras formas de vida, torna-se claro que a dimensão da população humana é excessiva. A questào populacional, analisada de um ponto de vista global, não é uma problemática apenas de países pobres, mas um elemento a ser considerado em termos de sustentabilidade geral. Para Naess (1989) o desenvolvimento de uma sociedade ecologicamente sustentável, na qual os seres humanos realizem suas metas últimas, requer uma diminuição do crescimento da população humana.

A questão populacional é vista como um problema complexo que não se apresenta da mesma forma em países ricos e em países pobres, onde o grau e os tipos de impacto são diferentes. Se nos países ricos temos um nível de consumo extremamente elevado, nos paises pobres temos uma grande concentração populacional, ambos com profundos efeitos sobre a 
sobrevivência e manutenção de ecossistemas. A análise desta questão é extremamente complexa e necessita ser realizada com mais profundidade do que será possível nos limites deste trabalho, mas vale ressaltar que, conforme exposto por McLaughlin (1993), existem evidências suficientes a indicar que a melhor forma de se moderar e reverter o crescimento populacional é a busca de soluções que promovam um padrão de vida aceitável para todos.

Talvez existam inúmeras razões psicológicas profundas que tornam muitas vezes bastante incomoda, para diversas pessoas, a proposta e a possibilidade de controle populacional. Talvez nossa abordagem cultural extremamente antropocêntrica não permita, muitas vezes, um olhar mais objetivo ou menos apaixonado sobre a questão.

\section{Ponto 5}

A presente interferência bumana sobre o mundo não bumano é excessiva e a situação está piorando rapidamente.

Segundo Devall \& Sessions (1985) o que está aqui colocado não é uma questão de interferência humana versus natureza intocada, mas muito mais o grau e extensào das modificações, e hoje parece provável que a combinação de vários efeitos como a deposição de substâncias ácidas, a redução da camada de ozônio, o aumento no ritmo de extinção de espécies, os processos de desertificação, deflorestamentos e poluição por resíduos tóxicos esteja mudando padrões climáticos mundiais e causando mudanças irreversíveis em grandes áreas da Terra.

Existem para McLaughlin (1993) pelo menos duas formas de interferência que necessitam ser abordadas. Uma é a destruição de áreas silvestres, como as florestas de zonas temperadas e as florestas tropicais, que é um fato irreparável a médio prazo e que impede a continuidade da história biológica. A outra forma de interferência a considerar é a determinada por formas particulares de tecnologia, já que muitas formas de interação com a natureza destróem seus ciclos muito mais do que o necessário, como por exemplo as práticas agrícolas modernas. 
$\mathrm{Na}$ visào de $\mathrm{McL}$ aughlin

\begin{abstract}
"observar diferenças de intensidade de interferência entre várias formas de tecnologia também aponta para uma importante dimensão da problemática populacional. Embora o maior crescimento populacional esteja projetado para ocorrer em paises menos desenvolvidos, as populações de paises industriais têm um impacto muito maior por pessoa na biosfera. As populajōes pobres de paises menos desenvolvidos que exploram áreas para obter madeira para cozinhar seus alimentos certamente criam certos problemas como um aumento em deflorestamentos e alagamentos, mas os automóveis dirigidos por pessoas de paises industrializados geram grandes quantidades de dióxido de carbono cada ano. Ao pensar sobre tais problemas é essencial lembrar que padrões de vida industrial impactam a biosfera muito mais profundamente do que aqueles dos paises pobres". (1993, p.183)
\end{abstract}

Devall \& Sessions (1985) colocam ainda que a idéia de "não interferência" nào implica que os seres humanos não poderiam modificar alguns ecossistemas como o fazem outras espécies. Os seres humanos têm modificado a Terra e provavelmente continuarão a fazê-lo, entretanto a questão é a natureza e a extensão de tal interferência pois, segundo os autores, áreas selvagens ou semi-selvagens são necessárias para permitir o processo evolutivo de espécies animais e vegetais.

\title{
Ponto 6
}

Os pontos acima mencionados indicam que mudanças são necessárias na forma dominante com que os seres bumanos até agora têm se comportado em suas relações com a Terra como um todo. As mudanças irão de uma maneira fundamental afetar estruturas políticas, sociais, tecnológicas, econômicas ou ideológicas.

Segundo Naess (1989), várias mudanças políticas são necessárias pois a noção de crescimento econômico que temos hoje, e a forma como ela é implementada em sociedades industriais, é incompativel com os pontos (1) e (5). Devall \& Sessions (1985) apontam para a existência de uma grande distancia entre formas sustentáveis ideais de crescimento econômico e as atuais políticas de paises industriais. 
A amplitude das mudanças necessárias é grande, mas um trabalho significativo para criar modelos adequados está sendo feito, na opinião de McLaughlin (1993). Para este autor, embora o conceito de sustentabilidade ainda seja um pouco obscuro, ele começa a apontar uma forma de como as nossas economias deveriam ser reestruturadas, mesmo entre aqueles que ainda se mantêm dentro de uma perspectiva antropocêntrica. $\mathrm{E}$ o fato de perspectivas econômicas, tecnológicas e ideológicas estarem interconectadas torna o problema amplo, mas pode determinar que uma mudança real em uma destas áreas facilite mudanças em outras.

\section{Ponto 7}

A mudança ideológica em paises ricos será principalmente a de um aumento no reconbecimento de qualidade de vida muito mais do que um alto padrão de vida material, desta forma, preparando um estado global para um desenvolvimento ecologicamente sustentável

Segundo Naess (1989), alguns economistas criticam o termo qualidade de vida pelo fato de ele ser muito vago, mas o que é considerado vago é na realidade sua natureza não quantitativa pois não é possivel quantificar adequadamente o que é importante para qualidade de vida da forma da maneira como ele está discutindo o assunto e conclui que não há necessidade para isto.

McLaughlin (1993) salienta que este ponto é extremamente importante para aqueles envolvidos em um profundo consumismo e que o apreço à qualidade de vida ao invés de quantidade de coisas leva a um aumento da felicidade e nào a um decréscimo. Para ele, o termo sustentabilidade de uma forma geral ainda significa sustentabilidade em relação a seres humanos e esta abordagem parece nào considerar que os ecossistemas e as interrelações ecológicas incluem os humanos e não existe na realidade uma relação humanos aqui e não humanos lá. Esta perspectiva pode funcionar no curto prazo, mas quando se leva em consideração o longo prazo este elemento não funciona pois a manutenção e o desenvolvimento da vida como 
um todo exige uma visão ampla e de longo prazo que leve em conta o aspecto abrangente da questão ambiental. Julgar sempre possível uma solução tecnológica para eventuais problemas é não levar em consideração que na realidade nós desconhecemos o real funcionamento dos ecossistemas e que mesmo soluções aparentemente ideais para o presente podem em um longo prazo ser nocivas para o meio ambiente. Sustentabilidade para ser verdadeira exige um raciocínio inclusivo, amplo e de longo prazo, e este conceito nào existe se a perspectiva é antropocêntrica. Para McLaughlin (1993), prudência, cautela e humildade deveriam estar sempre presentes nas relações dos seres humanos com o mundo interno e externo.

\section{Ponto 8}

Aqueles que subscrevem os pontos mencionados acima têm uma obrigação direta ou indireta de tentar implementar as mudanças necessárias através de meios não violentos.

$\mathrm{Na}$ visão de Naess (1989) há espaço suficiente para diferentes opiniões sobre prioridades e em função da valorização da diversidade elas devem ser respeitadas. Devall \& Sessions (1985) colocam que tais divergências são saudáveis para o movimento e discussões dentro de um espírito de respeito mútuo podem acrescentar novas dimensões e revelar abordagens criativas à crise ambiental. Para eles, diversas questões necessitam respostas, tais como: $\mathrm{O}$ que deve ser feito primeiro? $\mathrm{E}$ depois? $\mathrm{O}$ que é mais urgente? $\mathrm{O}$ que é necessário em oposição ao que é altamente desejável mas não absolutamente urgente?

Segundo Naess (1989), os pontos acima podem ser úteis para muitos que apoiam o movimento em ecologia profunda; outros irão certamente achar que eles são imperfeitos ou mesmo errôneos, mas se necessitarem formular em poucas palavras o que é básico na ecologia profunda proporão uma série de sentenças alternativas e sugere que deve haver um grau de diversidade no que é considerado básico e comum.

Naess (1989), argumenta que o que ele está elaborando não é uma filosofia em sentido acadêmico, nem um movimento institucionalizado 
como uma religião ou ideologia. Segundo ele, várias pessoas se reúnem em campanhas $\mathrm{e}$ ações diretas, formam um círculo de amigos que apóiam o mesmo tipo de estilo de vida, o qual os outros denominam "simples" mas que elas acham rico e variado. Por estas razões ele prefere o termo movimento muito mais que filosofia.

\section{ECOlogia Profunda E ECOLOGIA SUPERFICIAL: ALguMAS DISTINÇÕES BÁSICAS}

Arne Naess e outros autores que têm contribuído para a estruturação e definição da ecologia profunda têm procurado também delimitar e determinar as diferenças entre a ecologia profunda e a superficial. Segundo Naess (1989), uma série de abordagens ou perspectivas torna possivel fazer a distinção entre os dois movimentos. A análise de algumas questões presentes no debate ambiental tais como poluiçào, recursos naturais, populaçào, diversidade cultural e tecnologia apropriada, abordagens éticas com relação ao meio ambiente, educação $\mathrm{e}$ empreendimentos científicos, serão consideradas na tentativa de se clarear os contrastes. As diferenças apontadas a seguir são em sua maioria extraídas de trabalhos do próprio Naess.

\section{Poluição}

$\mathrm{Na}$ abordagem superficial procura-se, por exemplo, através da tecnologia purificar o ar e a água e reduzir a poluição; as leis elaboradas limitam poluições permissíveis e as indústrias poluidoras são de preferência exportadas para países em desenvolvimento.

$\mathrm{Na}$ abordagem profunda a poluição é avaliada a partir de um ponto de vista biosférico, não centrada em seus efeitos à saúde humana mas à vida como um todo, incluindo as condições de vida de cada espécie e ecossistema. 
A reaçào superficial à chuva ácida é retardar ações concretas enquanto são desenvolvidas mais pesquisas na busca de espécies de árvores tolerantes à acidez, maiores conhecimentos sobre seus efeitos etc., enquanto na visão profunda, a abordagem se concentra no que está ocorrendo no ecossistema total e exige como alta prioridade uma ação contra os sistemas econômicos e tecnológicos responsáveis pela sua formação. Em vez de concentrar a ação em soluções apenas técnicas questiona-se a situação como um todo, procurando verificar a causa fundamental do problema. A prioridade é lutar contra as causas profundas da poluição e não meramente contra efeitos superficiais de curto alcance. A exportação da poluição é vista não somente como um crime contra a humanidade, mas também contra a vida.

\section{Recursos}

$\mathrm{Na}$ abordagem superficial a ênfase é sobre recursos para humanos. Nesta visão os recursos da terra pertencem àqueles que têm tecnologia para explorá-los, ou seja às sociedades ricas. Existe confiança que os recursos nào serão esgotados, pois na medida em que eles se tornarem raros o alto preço de mercado irá conservá-los e substitutos serão encontrados através de progresso tecnológico. Além disto, animais, vegetais e objetos naturais são valiosos somente como recursos para seres humanos, se nenhum valor humano é conhecido, eles podem ser destruídos com indiferença.

Na abordagem profunda a preocupação é com recursos e habitat para todas as formas de vida. Nenhum objeto natural é concebido somente como um recurso e isto conduz a uma avaliação crítica dos modelos humanos de produção e consumo. Desta forma, questiona-se em que medida um aumento de produção e consumo favorece valores básicos para a vida humana; em que medida isto satisfaz necessidades vitais local e globalmente; de que forma instituições econômicas e educacionais podem ser modificadas para neutralizar aumentos de produção e consumo 
destrutivos, e como o uso de recursos pode servir à qualidade de vida e não a um padrão econômico como o geralmente promovido pelo consumismo. Há uma ênfase em uma abordagem ecossistêmica muito mais do que a consideração de formas de vida isoladas ou situações locais.

\section{População}

Na abordagem superficial o risco de uma superpopulação humana é visto principalmente como um problema em países em desenvolvimento e a questão da população ótima de seres humanos é discutida sem referência à questão da população ótima de outras formas de vida. A destruição de habitats naturais causada por um aumento da população humana é aceita como um mal inevitável e decréscimos drásticos nas formas de vida silvestres são geralmente aceitos, desde que as espécies não sejam levadas à extinção. Um controle a longo prazo da população humana não é visto como meta desejável.

$\mathrm{Na}$ abordagem profunda considera-se que existe uma pressão significativa nas condições de vida do planeta devido a um aumento da população humana. Em funçào da pressão global que as sociedades industriais exercem em termos ambientais, uma redução na população destas sociedades deveria ser de alta prioridade da mesma forma como em países em desenvolvimento. Esta redução possibilitaria, em função de um aumento de habitats, um crescimento na população de milhares de espécies que agora se encontram reduzidas por pressões humanas.

\section{Diversidade cultural e tecnologia apropriada.}

$\mathrm{Na}$ abordagem superficial o tipo de industrialização existente no ocidente é tomada como meta para países em desenvolvimento. A adoção universal de tecnologias de países desenvolvidos é compativel com moderada diversidade cultural e a conservação dos bons (do ponto de vista oci- 
dental) elementos das sociedades pré-industriais. Existe uma baixa estima com relação a profundas diferenças culturais que desviam significativamente dos padrões ocidentais.

$\mathrm{Na}$ abordagem profunda a diversidade cultural é semelhante no nível humano à riqueza $\mathrm{e}$ diversidade de formas de vidas biológicas. Deveria ser dada alta prioridade à educação em antropologia cultural em sociedades industriais, bem como limitar o impacto de tecnologias ocidentais sobre países não industrializados. Programas políticos e econômicos deveriam favorecer subculturas dentro de sociedades industrializadas. Tecnologias locais brandas deveriam permitir uma avaliação básica de qualquer inovação técnica, criticando livremente as chamadas tecnologias avançadas e conceitos de progresso.

\section{Abordagens éticas com relação ao meio ambiente}

$\mathrm{Na}$ abordagem superficial, paisagens, ecossistemas, rios e outros conjuntos naturais são divididos em fragmentos, desprezando-se unidades maiores e seus processos, que são observados como propriedade e recursos de individuos, organizaçòes ou estados. A conservação é analisada em termos de análises de custo/benefício, onde custos sociais e custos ecológicos de longo termo não são incluídos. O gerenciamento da vida silvestre conserva a natureza para futuras gerações de humanos e problemas como a erosão do solo ou a perda da qualidade da água subterrânea são observados como uma perda para humanos, mas uma forte crença em um futuro progresso tecnológico torna mudanças profundas desnecessárias.

Na abordagem profunda a Terra não é considerada como pertencente aos seres humanos, os quais habitam suas áreas e deveriam usar os recursos para satisfazer suas necessidades vitais. A destruição que ocorre no mundo natural não será solucionada por mudanças tecnológicas. 


\section{Educąão e empreendimentos cientificos}

$\mathrm{Na}$ abordagem superficial a reversão dos processos de degradação ambicntal e de esgotamento de recursos impõe a capacitação e formação de especialistas que possam orientar em como combinar crescimento econômico com manutenção de um meio ambiente sadio. Considera-se provável a necessidade de intensa interferência tecnológica quando o crescimento econômico global tornar uma degradação adicional inevitável. Os empreendimentos científicos devem dar prioridade às ciências duras, o que determina a necessidade de padrões educacionais com intensa competição.

Para a abordagem profunda a educação deveria concentrar-se em um aumento na sensibilidade para bens duráveis ou em bens de consumo, quando estes fossem suficientes para todos e desde que programas ccológicos sadios fossem adotados. A educação desta forma iria neutralizar a excessivo consumismo. Deveria haver uma mudança de ênfase de ciências duras para ciências brandas, enfatizando-se culturas globais e locais. A ecologia profunda questiona insistente e continuamente nào assumindo nada como garantido.

\section{COMENTÁRIOS}

Dentre os elementos centrais colocados pela Ecologia Profunda está a superação da visão antropocêntrica que tem moldado nossa cultura, e assim conceitos como auto-realização, valor intrínseco e identificação têm sido analisados por Naess (1989) dentro desta perspectiva.

Auto-realização está relacionada com a percepção e incorporação pela consciência humana do princípio ecológico de interconexão, com o fato de todas as individualidades estarem interligadas, formando um todo maior e extremamente complexo. Auto-realização não é visto, na Ecologia Profunda, como um estágio a ser atingido, mas um estado de ser em contínua expansão que vai incluindo outras pessoas, espécies e a própria nature- 
za, de forma que todos passem a fazer parte do interesse humano. Este estado conduz aos outros dois conceitos, de identificação, no sentido de se considerar as necessidades vitais de outros seres e ecossistemas com o mesmo grau em que se considera as humanas, e de valor intrínseco, que surge com a idéia de igualdade biocêntrica.

O significado atribuido por Naess (1989) a estes conceitos encontra paralelo em outros sistemas filosóficos, como por exemplo, em certas tradições Budistas onde a idéia de auto-realização, de alcançar o Nirvana, é vista como um processo, um modo de vida, uma vez que este estado não é alcançado individualmente mas todos os seres humanos e não humanos o farão ao mesmo tempo (Batchelor, 1992).

A implementação destas idéias, como incorporá-las no cotidiano, não é explicitado pela Ecologia Profunda e, segundo Naess (1989), isto é proposital de forma que diferentes pessoas e culturas em diferentes situações busquem caminhos diversos, o que tem determinado diversas críticas, entre as quais de ser um movimento utópico, não criativo, que apresenta críticas a estrutura sócio-econômica ambiental atual mas não aponta caminhos práticos possiveis (Colby, 1991).

Para McLaughlin (1993), independente de apresentar aspectos que necessitem maiores esclarecimentos e das críticas que tem recebido, a Ecologia Profunda tem contribuído significativamente no debate sobre o papel da visão antropocêntrica na problemática ambiental e na compreensão das relações dos seres humanos com a natureza e com eles mesmos.

Esta opiniào também poderia ser atribuida a Krishnamurti em seu comentário:

“...como não amamos a terra e as coisas da terra mas simplesmente as utilizamos... perdemos o contato com a vida... Perdemos o sentimento de ternura, a sensibilidade, e a noção de beleza; e será somente na renovação desta sensibilidade que iremos recuperar a compreensão do que é um verdadeiro relacionamento". (1992, p.01) 
ABSTRACT: This article presents the basic ideas from the Deep Ecology Movement, mainly the approach developed by Arne Naess and discuss the distinctions pointed by Naess and others authors between Deep and Shalow Ecology.

KeYwords: Deep Ecology, Ecophilosophy, Sustentability, Intrinsic Value, Antropocentrism, Environmental Problems, Social Movement.

\section{BIBLIOGRAFIA CONSULTADA}

BATCHELOR, M. \& BROWN, K. Buddhism and ecology. London, Cassel,1992.

DEVALL, B. Living richly in an age of limits. Layton, Gibbs Smith, 1993.

DEVALL, B. \& SESSIONS, G. Deep ecology. Layton, Gibbs Smith, 1985.

FOX, W. Toward a transpersonal ecology. London, Shambhala, 1990.

KRISHNAMURTI, J. On nature and the environment. London, Victor Gollancz, 1992.

McLAUGHLIN, A. Regarding nature - Industrialism and deep ecology. New York SUNY Press, 1993.

NAESS, A. The deep ecological movement: some philosophical aspects. 1986. mimeo. Ecology, community and lifestyle. New York, Cambridge University Press, 1989.

A note on the prehistory and history of the deep ecology movement. 1989a. mimeo.

ROTHENBERG, D. Is it painful to think? Conversations with Arne Naess. Minneapolis, University of Minnesota Press, 1993.

SESSIONS, G. Deep ecology for the 21st Century. Boston, Shambhala, 1994. 